\title{
Mueller-Hillis maneuver and angle of progression: Are they correlated?
}

\author{
Sofia Mendes ${ }^{1 *}$, Rita Silva ${ }^{1}$, Inês Martins ${ }^{1}$, Susana Santo ${ }^{1}$, Nuno Clode $^{1}$ \\ ${ }^{1} \mathrm{MD}$, Department of Obstetrics, Gynecology and Reproductive Medicine, Hospital de Santa Maria, Lisboa, Portugal
}

Study conducted at the Departamento de Obstetrícia, Ginecologia e Medicina da Reprodução, Hospital de Santa Maria, Lisboa, Portugal

Article received: $11 / 24 / 2016$ Accepted for publication: 12/4/2016

*Correspondence: Departamento de Obstetrícia, Ginecologia e Medicina da Reprodução, Hospital de Santa Maria Address: Av. Prof. Egas Moniz Lisboa - Portugal

Postal code: 1649-035 sofiamendes01@gmail.com

http://dx.doi.org/10.1590/1806-9282.63.06.527

\section{SUMMARY}

Objective: Mueller-Hillis maneuver (MHM) and angle of progression (AOP) measured by transperineal ultrasound have been used to assess fetal head descent during the second stage of labor. We aimed to assess whether AOP correlates with MHM in the second stage of labor.

Method: A prospective observational study including women with singleton pregnancy in the second stage of labor was performed. The AOP was measured immediately after the Mueller-Hillis maneuver. A receiver-operating characteristics (ROC) curve analysis was performed to determine the best discriminatory AOP cut-off for the identification of a positive MHM. A p-value less than 0.05 was considered statistically significant.

Results: One hundred and sixty-six (166) women were enrolled in the study and $81.3 \%(n=135)$ had a positive MHM. The median AOP was $143^{\circ}\left(106^{\circ}\right.$ to $\left.210^{\circ}\right)$. The area under the curve for the prediction of a positive maneuver was 0.619 $(\mathrm{p}=0.040)$. Derived from the ROC curve, an AOP of $138.5^{\circ}$ had the best diagnostic performance for the identification of a positive MHM (specificity of $65 \%$ and a sensitivity of $67 \%$ ).

Conclusion: An AOP of $138^{\circ}$ seems to be associated with a positive MHM in the second stage of labor.

Keywords: second stage of labor, angle of progression, Mueller-Hillis maneuver, intrapartum, ultrasonography.

\section{INTRODUCTION}

Spontaneous vaginal delivery is the desirable mode of delivery for most pregnancies. However, some women fail to progress into second stage of labor and require obstetric intervention. Progression of labor is traditionally assessed by digital examination. In 1885 , Mueller ${ }^{1}$ described a maneuver in which an assistant applies fundal pressure and a second examiner determines descent of the fetal presenting part. The technique was modified by Hillis ${ }^{2}$ in 1930 to allow its execution by a single person, and later became known as Mueller-Hillis maneuver (MHM). According to March et al., a positive Mueller-Hillis maneuver should reassure the clinician of an exceptional likelihood of achieving a vaginal delivery. ${ }^{3}$ Thorp et al. ${ }^{4}$ however, failed to prove its utility to predict dystocia. Moreover, for the determination of fetal head station, several other studies showed that digital vaginal examination ${ }^{5-7}$ is subjective with high inter-observer variability. Intrapartum transperineal ultrasonography (ITU) has been suggested as a much more reliable method for assessing fetal head descent, as it provides objective and reproducible results. ${ }^{8}$ It is neither time-consuming nor causes discomfort of the patient. ${ }^{9}$ However, it may not be available everywhere. The angle of progression measured by transperineal ultrasound in the second stage of labor has been shown to be useful in predicting spontaneous vaginal delivery. ${ }^{10,11}$

The aim of our study was to assess whether the angle of progression correlates with the Mueller-Hillis maneuver in the second stage of labor.

\section{Method}

From November 2014 to September 2015, we conducted a prospective observational study at our unit. Pregnant women with a single fetus in cephalic presentation in the early second stage of labor were included.

The examination was performed using the modified Mueller-Hillis maneuver. With the patient in lithotomy position, the examining fingers were inserted into the vagina and the ischial spines and fetal head were identified. Pressure was then applied transabdominally with the op- 
posite hand on the uterine fundus. The descent of the head with reference to the interspinous line was evaluated. The examination was performed between contractions. A positive Mueller-Hillis maneuver was defined as descent of the fetal head of at least one centimeter. Any lesser degree of descent was defined as a negative result. After clinical evaluation, transperineal ultrasound was performed. The ultrasound transducer was placed on the perineum in a mid-sagittal position between the labia, below the pubic symphysis. A sagittal view with clear visualization of the pubic symphysis and of the fetal skull was obtained. Two lines were drawn: a line parallel to the long axis of the symphysis and a line tangential to the fetal head. The so-called angle of progression between the constructed lines was then measured directly on the screen and registered on each patient file. ${ }^{10}$ The measurement was performed between contractions.

Both examinations were performed by eight different clinicians with at least two years of experience. All of them received training on how to do transperineal ultrasound. MHM and $\mathrm{AOP}$ were measured by two different clinicians that were blinded to the findings of each other in order to avoid bias.

For ultrasound evaluation, we used a portable machine (ALOKA ${ }^{\circledR}$ IP-1233).

Baseline sociodemographic and clinical characteristics were summarized using descriptive statistics. The primary endpoint was to assess the correlation between AOP and a positive Mueller-Hillis maneuver, which was evaluated using a receiver-operating characteristic (ROC) curve. Additionally, an analysis to assess if AOP or MHM influenced the type of delivery (normal vs. instrumental) was performed.

Chi-square test was used to evaluate nominal variables and ANOVA, t-test and Kruskall-Wallis were used for quantitative variables. Results were considered statistically significant when $\mathrm{p}$-value was $<0.05$. The statistical analysis was performed using SPSS software version 20.0.

\section{Results}

One hundred and sixty-six (166) women were enrolled during the study. The mean maternal age was $30.1( \pm 5.3)$ years. The mean gestational age was $39.1( \pm 1.4)$ weeks. One hundred and one (101/60.8\%) women were nuliparous and $65(39.2 \%)$ were multiparous. Oxytocin was administered to $161(97 \%)$ women and regional anesthesia was given to 164 (98.7\%) women. Seventy-five (75) women had normal vaginal delivery, while 91 had instrumental vaginal delivery and, of these, two had a failed trial of instrumental delivery and one had cesarean section. The mean birth weight of newborns was 3,305 $( \pm 392)$ grams. The patient characteristics are shown in Table 1.
TABLE 1 Description of study population -

patient characteristics.

N (\%) or median (range)

\begin{tabular}{ll}
\hline Age (years) & $31(15-43)$ \\
\hline Race & $141(84.9)$ \\
Caucasian & $22(13.3)$ \\
African & $3(1.8)$ \\
Other & \\
\hline Parity & $101(60.8)$ \\
Nuliparous & $65(39.2)$ \\
Multiparous & $39(32-41)$ \\
\hline Gestational age (weeks) & $7(4.2)$ \\
$<37$ & $159(95.8)$ \\
$\geq 37$ & \\
\hline Body mass index & $133(80.1)$ \\
$<30$ & $33(19.9)$ \\
$\geq 30$ & \\
\hline Labor induction & $53(31.9)$ \\
Yes & $110(66.3)$ \\
No & $16(97)$ \\
\hline Labor augmentation with oxytocin & $5(3)$ \\
Yes & $164(98.7)$ \\
No &
\end{tabular}

Delivery

Mode of delivery

Normal 75 (45.2)

Instrumental vaginal delivery $\quad 89(53.6)$

Prolonged $2^{\text {nd }}$ stage of labor $\quad 70(78.6)$

Fetal distress $15(16.8)$

Shorten the $2^{\text {nd }}$ stage of labor

Cesarean section $4(4.5)$

Failure to progress in $2^{\text {nd }}$ stage of labor $2(1.2)$

Fetal birth weight $(\mathrm{g}) \quad 3,282(2,100-4,410)$

Apgar score $<7$ at the $5^{\text {th }}$ minute $\quad 0$

The median AOP was $143^{\circ}\left(106^{\circ}\right.$ to $\left.210^{\circ}\right)$. One hundred and thirty-five (135/80.8\%) women had a positive MHM. A ROC curve was plotted, evaluating the sensibility and specificity of each measured AOP for predicting a positive/negative MHM. The area under the ROC curve was 0.619 (95CI $0.493-0.745$ ), suggesting a poor performance of AOP for the prediction of the maneuver (Figure 1). Considering the whole range of measured AOP, an angle of $138.5^{\circ}$ was associated to the maximum Youden index and therefore to the best performance (66.7\% sensibility and $64.5 \%$ specificity) on MHM prediction. 


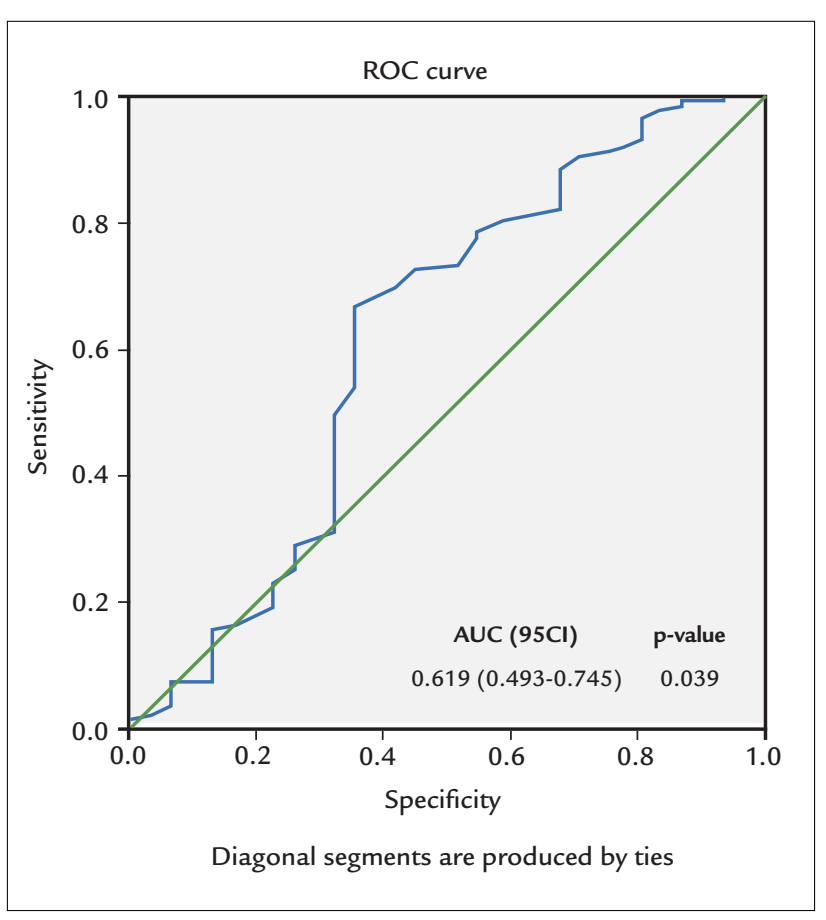

FIGURE 1 ROC curve to determine the best discriminatory AOP cut-off for the identification of a positive MHM.

No differences were found in AOP considering fetal position, but the proportion of positive/negative MHM was significantly different between anterior and transverse positions. Regarding the AOP or MHM and fetal head stations no significant differences were noted (Table 2). Moreover, no differences between the type of delivery and AOP or MHM were found. However, when instrumental vaginal delivery for fetal distress or shortening of the $2^{\text {nd }}$ stage were excluded, the difference became statistically significant for both methods (Table 3 ).

\section{Discussion}

The main objective of the obstetrician is to promote the safe birth of a healthy baby. Most births occur vaginally and spontaneously; however, there are situations in which this is not possible. The success of an instrumental vaginal delivery depends on a proper obstetric assessment prior to the procedure. Patients who are inappropriately qualified for vaginal instrumental delivery (too high position of fetal head) are at an increased risk of complications after multiple vacuum traction or failed forceps procedure. The Mueller-Hillis maneuver constitutes one of the first attempts to predict dystocia. Thorp et al. ${ }^{4}$ performed MHM on 106 pregnant women after active labor was diagnosed. The authors couldn't find any differences in the rate of abdominal delivery or operative vaginal delivery whether the maneuver was positive or negative. On the other hand, March et al. ${ }^{3}$ concluded that a positive maneuver in the second stage of labor is strongly associated with a vaginal delivery and that a negative one associates significantly with prolonged second stage, and higher cesarean section rate. Despite these conflicting results and lack of other studies, the Mueller-Hillis maneuver is still being used.

Intrapartum ultrasound has been suggested to overcome the subjectivity of clinical assessment. Various ultrasound measurements have been proposed. The angle of progression was describe by Barbera et al. ${ }^{10}$ who showed that an angle of at least $120^{\circ}$ was always associated with subsequent spontaneous vaginal delivery with a good intraand inter-observer variability. Torkildsen et al. ${ }^{11}$ and Eggebo et al. ${ }^{12}$ reported that for primiparous women with prolonged first stage of labor, the AOP could predict the probability of a vaginal delivery being the optimal cut-off $110^{\circ}$. Kalache et al. ${ }^{13}$ reported that for pregnant women in a prolonged second stage of labor, there is a $90 \%$ chance of vaginal delivery with an $\mathrm{AOP}$ of $120^{\circ}$. However, the value of $\mathrm{AOP}$ associated with spontaneous delivery is not consensual, since studies pointed out higher values for AOP. ${ }^{14,15}$

Globally, in our study, AOP showed a poor correlation with MHM, indicated by a low AUC. Nevertheless, we have found that AOP over $138.5^{\circ}$ had the best diagnostic performance for the identification of positive MHM in the early second stage of labor but with a low sensibility and specificity that preclude its use for clinical practice.

We included women with indication to expedite delivery not only due to dystocia but also to fetal distress. None of the methods are expected to be used to predict situations that require prompt obstetric interventions. In fact, when excluding cases of fetal distress/shortened second stage of labor, both AOP and MHM seemed to be associated with type of delivery. The main purpose of our study, however, was to find a relation between the maneuver and $\mathrm{AOP}$ and not between both methods and the type of delivery. Nevertheless, a subanalysis was made excluding cases of fetal distress, and the results were similar (data not shown).

To our knowledge, ours is the first study to correlate MHM with AOP; however, there are important limitations. We made a single measurement of the AOP after MHM but, since labor is a dynamic process, repeating measurements of both angle and MHM every 30 minutes might be helpful. In fact, Ghi et al. ${ }^{14}$ reported that, in the first 40 minutes of the second stage of labor, AOP was useful for predicting mode of delivery but afterwards the difference lost its statistical difference. Moreover, as previ- 
TABLE 2 Position and head station - only assessed by clinical examination.

\begin{tabular}{|c|c|c|c|c|c|c|}
\hline & \multirow[t]{2}{*}{$\mathrm{N}(\%)$} & \multirow[t]{2}{*}{ Median AOP (range) } & \multirow[t]{2}{*}{ p-value } & \multicolumn{2}{|c|}{ MHM } & \multirow[t]{2}{*}{ p-value } \\
\hline & & & & Positive & Negative & \\
\hline \multicolumn{7}{|l|}{ Position } \\
\hline Anterior & $105(63.3)$ & $143(108-210)$ & \multirow[t]{3}{*}{0.288} & 90 & 14 & \multirow[t]{3}{*}{0.020} \\
\hline Posterior & $47(28.3)$ & $142(106-179)$ & & 37 & 11 & \\
\hline Transverse & $14(8.4)$ & $141(123-165)$ & & 8 & 6 & \\
\hline \multicolumn{7}{|l|}{ Head Station } \\
\hline$\leq 0$ & $22(13.2)$ & $135(123-163)$ & \multirow[t]{4}{*}{0.406} & 17 & 4 & \multirow[t]{4}{*}{0.310} \\
\hline 1 & $73(43.7)$ & $144(106-210)$ & & 56 & 17 & \\
\hline 2 & $62(37.1)$ & $142(113-179)$ & & 52 & 10 & \\
\hline 3 & $10(6.0)$ & $141.5(129-170)$ & & 10 & 0 & \\
\hline
\end{tabular}

TABLE 3 Type of delivery and MHM and AOP*.

\begin{tabular}{|c|c|c|c|c|c|}
\hline \multirow[t]{2}{*}{ Type of delivery $(N=147)$} & \multirow[t]{2}{*}{ Mean AOP (SD) } & \multirow[t]{2}{*}{ p-value } & \multicolumn{2}{|c|}{ MHM } & \multirow[t]{2}{*}{ p-value } \\
\hline & & & Positive & Negative & \\
\hline Normal & $145.33( \pm 13.7)$ & \multirow[t]{2}{*}{$0.034^{++}$} & 67 & 8 & \multirow[t]{2}{*}{$0.005^{* *}$} \\
\hline Instrumental vaginal delivery & $140.52( \pm 14.7)$ & & 67 & 22 & \\
\hline Cesarean section & $129.5( \pm 12.0)$ & & 1 & 1 & \\
\hline
\end{tabular}

ously recorded, ${ }^{16}$ uterine contractions and active maternal pushing seem to affect AOP in the second stage of labor. We made a single measurement of the AOP after the MHM and not during the maneuver and therefore we do not know if this could change the results.

In our study, both examinations were performed immediately after full cervical dilation was determined, i.e., in the early second stage of labor. Consistent timing for the examination enables a more accurate correlation of both methods but it is difficult to exactly assess the moment of full cervical dilation. Moreover, other variables might have affected the maneuver's outcome, such as maternal habitus, position of the head, flexion/extension of the head, force applied or resistance of the maternal abdomen. Fetuses presenting as occiput posterior position are thought to follow different paths of descent ${ }^{16}$ and, since we did not evaluate separately this subset of fetuses, which might have been a limitation of our study. Lastly, because ultrasound measurements and clinical assessments were performed by residents with different levels of experience, and this variable may influence the clinical evaluation, ${ }^{17}$ the inverse correlation between lower head station and higher AOP was not seen in our population.

If one method can predict spontaneous delivery with a high likelihood, it may prevent unnecessary obstetric interventions. The ideal method for obstetric assessment is one that is available worldwide, easy to perform and reproducible. Regardless of the individual value of the MHM and AOP as previously reported to predict the type of delivery (which is debatable in both methods), our data failed to find a strong correlation between these methods.

\section{Conflict of interest}

The authors declare no conflict of interest.

\section{Resumo}

Manobra de Mueller-Hillis e ângulo de progressão: eles estão correlacionados?

Objetivo: A manobra de Mueller-Hillis (MHM) e o ângulo de progressão da apresentação (AOP) medido através de ecografia transperineal têm sido utilizados para avaliar a descida do polo cefálico durante o segundo estágio do trabalho de parto. O objetivo do nosso trabalho foi avaliar se o AOP se correlaciona com a MHM no segundo estágio do trabalho de parto.

Método: Conduzimos um estudo observacional e prospectivo. Incluímos mulheres com gravidez unifetal com feto em apresentação cefálica, no segundo estágio do 
trabalho de parto. O AOP foi medido imediatamente após a manobra de Mueller-Hillis. Foi construída uma curva ROC (receiver-operating characteristics) para determinar o melhor AOP para a identificação de uma manobra positiva. Um valor p inferior a 0,05 foi considerado estatisticamente significativo.

Resultados: Cento e sessenta e seis mulheres (166) foram incluídas no estudo, e em 81,3\% ( $\mathrm{n}=135$ ) a MHM foi positiva. A mediana do AOP foi de $143^{\circ}\left(106^{\circ}\right.$ a $\left.210^{\circ}\right)$. A área abaixo da curva para a previsão de uma manobra positiva foi $0,619(\mathrm{p}=0,040)$. Derivado da curva ROC, um AOP de $138,5^{\circ}$ teve o melhor desempenho diagnóstico para a identificação de uma MHM positiva (especificidade de $65 \%$ e sensibilidade de $67 \%$ ).

Conclusão: $\mathrm{Um} \mathrm{AOP}$ de $138^{\circ}$ parece estar associado com uma MHM positiva no segundo estágio de trabalho de parto.

Palavras-chave: segundo estágio do trabalho de parto, ângulo de progressão, manobra de Mueller-Hillis, intraparto, ecografia.

\section{RefEREnCES}

1. Mueller P. About the prognosis for delivery with a narrow pelvis. Arch Gynaekol. 1885; 27:311-2.

2. Hillis DS. Diagnosis of contracted pelvis by impression method. Surg Gynecol Obstet. 1930; 51:852-4.

3. March MR, Adair CD, Veille JC, Burrus DR. The modified Mueller-Hillis maneuver in predicting abnormalities in second stage labor. Int Journal of Gynecology and Obstetrics. 1996; 55(2):105-9.

4. Thorp JM, Pahel-Short L, Bowes WA Jr. The Mueller-Hillis maneuver: can it be used to predict dystocia? Obstet Gynecol. 1993; 82(4 Pt 1):519-22.
5. Dupuis O, Silveira R, Zentner A, Dittmar A, Gaucherand P, Cucherat M, et al. Birth simulator: reliability of transvaginal assessment of fetal head station as defined by the American College of Obstetricians and Gynecologists classification. Am J Obstet Gynecol. 2005; 192(3):868-74.

6. Buchmann $\mathrm{E}$, Libhaber E. Interobserver agreement in intrapartum estimation of fetal head station. Int J Gynecol Obstet. 2008; 101(3):285-9.

7. Tutschek B, Torkildsen EA, Eggebo TM. Comparison between ultrasound parameters and clinical examination to assess fetal head station in labor. Ultrasound Obstet Gynecol. 2013, 41(4):425-9.

8. Chou MR, Kreiser D, Taslimi MM, Druzin ML, El-Sayed YY. Vaginal versus ultrasound examination of fetal occiput position during the second stage of labor. Am J Obstet Gynecol. 2004; 191(2):521-4.

9. Rozenberg P, Porcher R, Salomon LJ, Boirot F, Morin C, Ville Y. Comparison of the learning curves of digital examination and transabdominal sonography for the determination of fetal head position during labor. Ultrasound Obstet Gynecol. 2008; 31(3):332-7.

10. Barbera AF, Pombar X, Perugino G, Lezotte DC, Hobbins JC. A new method to assess fetal head descent in labor with transperineal ultrasound. Ultrasound Obstet Gynecol. 2009; 33(3):313-9.

11. Torkildsen EA, Salvesen KÅ, Eggebø TM. Prediction of delivery mode with transperineal ultrasound in women with prolonged first stage of labor Ultrasound Obstet Gynecol. 2011;37(6):702-8.

12. Eggebø TM, Hassan WA, Salvesen KÅ, Lindtjørn E, Lees CC. Sonographic prediction of vaginal delivery in prolonged labor: a two-center study. Ultrasound Obstet Gynecol. 2014; 43(2):195-201

13. Kalache KD, Dückelmann AM, Michaelis SA, Lange J, Cichon G, Dudenhausen JW. Transperineal ultrasound imaging in prolonged second stage of labor with occipitoanterior presenting fetuses: how well does the "angle of progression" predict the mode of delivery? Ultrasound Obstet Gynecol. 2009; 33(3):326-30.

14. Ghi T, Youssef A, Maroni E, Arcangeli T, De Musso F, Bellussi F, et al Intrapartum transperineal ultrasound assessment of fetal head progression in active second stage of labor and mode of delivery. Ultrasound Obstet Gynecol. 2013; 41(4):430-5.

15. Kameyama S, Sato A, Miura H, Kumagai J, Sato N, Shimizu D, et al. Prediction of spontaneous vaginal delivery by transperineal ultrasound performed just after full cervical dilation is determined. J Med Ultrasonics. 2016; 43(2):243-8.

16. Tutschek B, Braun T, Chantraine F, Henrich W. A study of progress of labour using intrapartum translabial ultrasound, assessing head station, direction, and angle of descent. BJOG. 2011; 118(1):62-9.

17. da Costa AG, Barros JG, Clode N, da Graça LM. Levels of agreement between clinical examination and transabdominal ultrasound evaluation of fetal head position in the second stage of labor. J Matern Fetal Neonatal Med. 2016; 29(3):473-6. 